\title{
Evaluation of Cavity Formation and the Use of Cut-off Wall to Reduce the Risk of Washing Subsurface Fine Material
}

\author{
Fouzan Alfouzan $^{1}$, Muawia A Dafalla ${ }^{2}$, Akeel Alharbi ${ }^{3}$ \\ ${ }^{1}$ Assistant Research Professor, King Abdulaziz City for Science and Technology, KACST, Saudi Arabia \\ ${ }^{2}$ Assistant Professor and Consultant, Civil Engineering, BRCES, King Saud University \\ ${ }^{3}$ Scientific Researcher, King Abdulaziz City for Science and Technology, KACST, Saudi Arabia
}

Received 2013

\begin{abstract}
This study shows the results of mapping numerous cavities and distress which appeared and detected in Qassim area, Saudi Arabia. This phenomenon was observed near a school building and residential area and became a serious risk to occupants and residents. The survey was carried out applying geotechnical techniques which included advancing rotary boreholes to depths of $23 \mathrm{~m}$ to $30 \mathrm{~m}$ with sampling and testing. The evaluation process also included resistivity imaging profiles using 2D electrical resistivity measurements. Results obtained from this research showed a thick top layer of silty clayey sand soil rich of gypsum and carbonate presenting a hazardous and high-risk soil type. The percentage of fines that are likely to be washed out as a result of chemical disintegration and exposure to significant hydraulic gradient was of great concern. Assessment was made using combined geotechnical and geophysical approach in addition to chemical tests. Based on the data collected and analysis of test results a practical solution was suggested to solve this problem. The use of "cut-off wall" in order to reduce the level of subsurface scour and cajuvity formation were found appropriate. The depth of the cut off wall was determined based on the subsurface geological profile. Advantages of this approach and concerns need to be considered in adopting typical solutions that are presented.
\end{abstract}

Keywords: Collapse; Cavities; Electrical Resistivity; Sarah Formation; Geotechnical Methods

\section{Introduction}

This study was conducted to investigate the cause of cracks and subsoil collapse appeared recently at a residential area in Authal Center, Al Qassim Region, and Central Saudi Arabia. The site investigation was conducted for locations within close vicinity to coordinates (N 26o 31' 17.8" E 43o 41' 22.2"). See Figure 1.

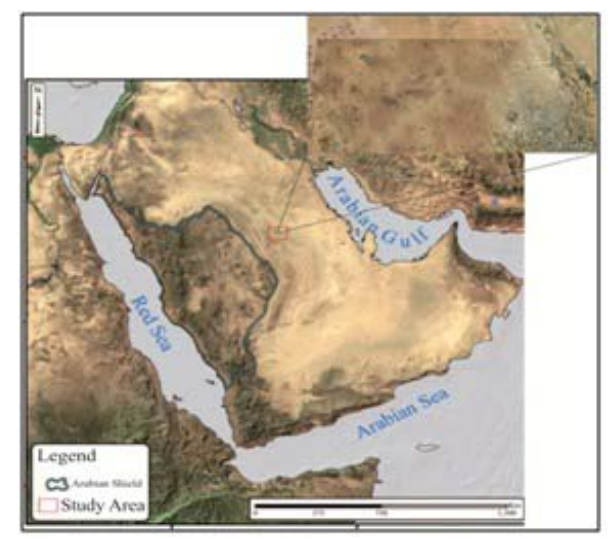

Figure1. Study Area Map (after of [1]).
The area was reported to have unusual subsidence and near surface cavities. The cause of these faults and collapse was obviously not related to human activities and expected to be a natural phenomenon. Investigation program included geotechnical engineering and geological assessment. In addition to these methods, a 2D geophysical resistivity imaging system was used. The following goals were planned to be achieved:

1) Evaluating of the thickness of surface soil layer.

2) Evaluating the subsurface geological features.

3) Evaluating depth of groundwater and surface water if found.

4) Evaluating the seriousness of current collapse and void formation hazards, at present and in future.

2D resistivity imaging system was used as to be one of the most known systems at present time to give two different cross-sections in different directions in investigated areas and environmental explorations. A geotechnical engineering study was conducted and both field and laboratory works were carried out. Results obtained through geophysical and geotechnical methods showed that the entire problem is related to the nature of the near 
surface soil layer. Loose spots of clayey sand were formed due to the loss of fine material being washed away. The subsurface soil was subjected to great hydraulic head difference created by topography and rainfall. When soils got wet and liquefied, interstitial pores increase, hollow tiny voids and vugs develop into fissures, cracks, big voids and then collapse by time (Figure 2).

Chemical disintegration of subsoil material can have a significant role in cavity formation especially when calcium and salts including carbonates and sulfates are present.

Calcium carbonate $\left(\mathrm{CaCO}_{3}\right)$ reacts with $\mathrm{CO}_{2}$ to form soluble calcium bicarbonate; $\mathrm{Ca}\left(\mathrm{HCO}_{3}\right)_{2}$. This can cause solid material to reduce and wash away with water.

This soluble compound is then washed away with the rainwater. This form of weathering is called 'Carbonation".

Calcium oxide can react with basic oxides to give calcium sulfites.

$$
\mathrm{CaO}+\mathrm{SO}_{2} \rightarrow \mathrm{CaSO}_{3}
$$

with oxidation of the $\mathrm{CaSO}_{3}$ gives $\mathrm{CaSO}_{4}$ or $\mathrm{Ca}$ $\mathrm{SO}_{4} \cdot \mathrm{N}\left(\mathrm{H}_{2} \mathrm{O}\right)$.

\section{Geology Setting}

Arabian Peninsula is formed of two main structures, the first is the Arabian Shield, which covers nearly $40 \%$ of the Arabian Peninsula in the West, and the second structure is the sedimentary formation which covers the remaining parts of the Kingdom, located dominantly towards the East. The formation of the Arabian Shield consists of solid basement rocks of [2] Proterozoic Eon (Precambrian), which is overlain by rocks that return in age to Paleozoic, Mesozoic and Cenozoic eras, forming rocks of the sedimentary basin in the sedimentary cover.

The study area lies on recent deposits of Quaternary Period in age, directly above Sara Formation of Early Silurian. Sara Formation is characterized and strongly influenced by lifting tectonic movements. Sara Formation is formed of different constituents, which include the two main components:

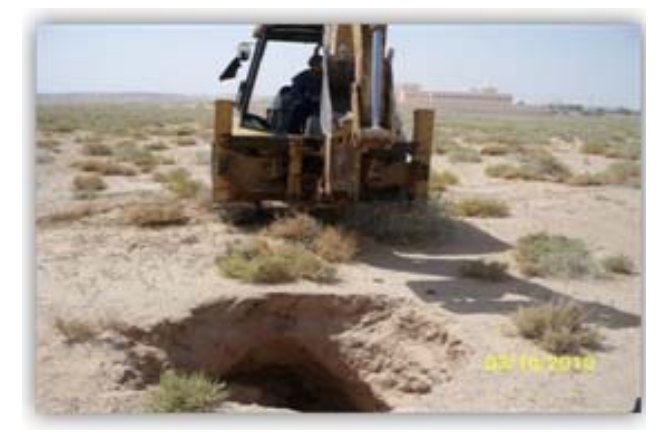

Figure 2. Typical sink hole close to ground surface.

1) Shale and silt, exposed at Jabal Khanasir Sara in Al
Qassim Region.

2) Tillite sandstone, exposed at Jabal as Zarqa, east of Hail. These rocks consist of heavy distribution of cross bedding structures.

The local site geology of the study area indicated the presence of Quaternary deposits of sand, clay and silt followed by weakly cemented sandstone. The sandstone cementation is improving with depth and getting sound and intact beyond $10 \mathrm{~m}$ below ground level.

The area under investigation lies on recent deposits of an active khabra, of Quaternary Period in age, Figure 3. It is located in a low area, compared to the surrounded topography. During the rainy season, the khabra is crossed by surface runoffs that drain rainfall and water flowing from the upstream drainage basin, in which the silt and clay carried by wadis settle, and natural vegetation flourishes.

The khabra deposits are typically silty and clayey with small amount of eolian sand and no pebbles or gravel. It looks like sand sheets of different sizes.

\section{Methodology}

\subsection{Geotechnical Tools}

The field work included advancing four boreholes that range in depth between 23 to $30 \mathrm{~m}$, below earth's surface, and also few open test pits excavated to a depth of 2 to 3 $\mathrm{m}$ below grade level. The boreholes and test pits were distributed in a way to cover the area next to school which showed many cavities and sink holes. The term sink holes used to denote cavities near surface in which the arching collapsed leaving an open hole. Figure 4 presents the drilling instrument used (Acker AD II) type, fixed on board International, 4-wheel drive truck.
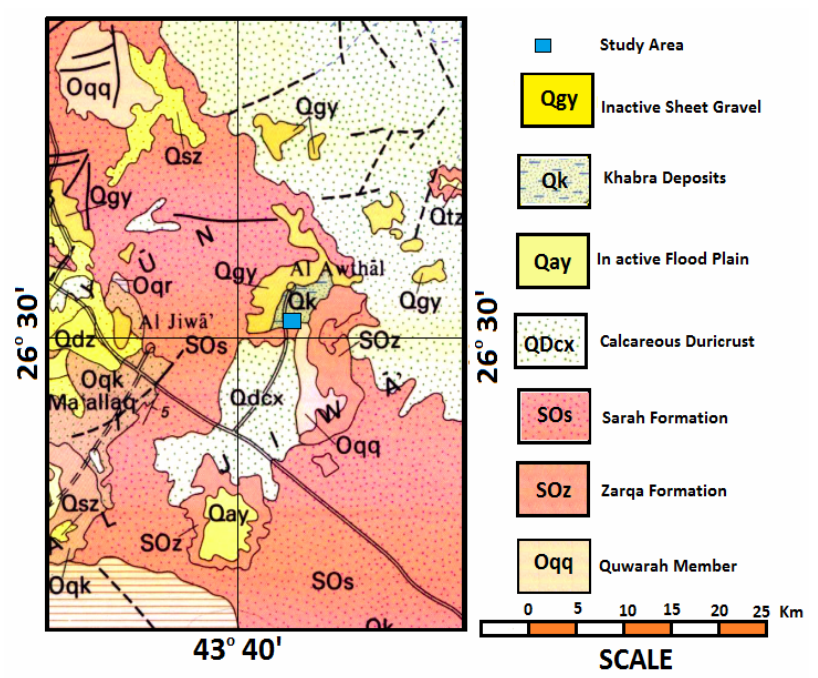

Figure 3. A geologic map of the study area within recent khabra deposits. 


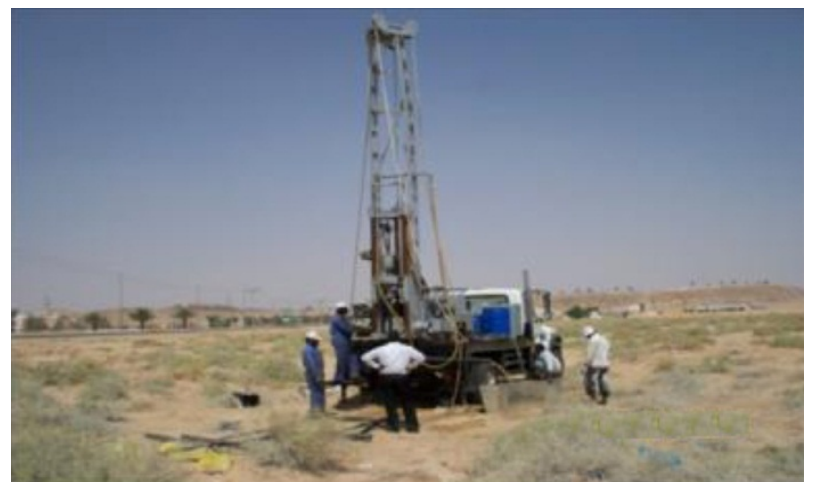

Figure 4. Acker AD II Drilling rig operating on site.

\subsection{D Resistivity Imaging System}

Syscal R1 system was used in field work. It is considered one of the most widely used systems at present time to give two different cross sections. It is mainly used for water and subsurface exploration. The (Syscal R1) is a multi-node resistivity imaging system. It features an internal switching board for 72 electrodes. The system is designed to automatically perform pre-defined sets of resistivity measurements with roll-along capability, with 3 meters electrode spacing.

This instrument is provided with three special programs, helping to design imaging methods and for data transfer from the instrument to the personal computer or laptop, and vice versa. They are used for initial analysis of data output at field and before using the sophisticated computer program for resistivity imaging meter (Res2Dlnv). The later program is one of the most advanced programs dealing with processing of resistivity output data analysis.

\section{Field Work and Data Collections}

\subsection{Boring Works}

Drilling within the upper layers was done by wash boring method, and in case of encountering hard soil layer, the rotary drilling is continued using tri-cone bit so as to help crossing the hard layer using casing. When firm rock is reached drilling is continued using a double tube core barrel of a two inch size (T2 76). This core barrel helps in extracting good quality core samples.

Four (4) open hole tests were excavated, 2 - 3 meter in depth, in order to study the constituents of the subsurface soil, to preview the possible cavities, to present a geologic and geotechnical description and to provide laboratory with some undisturbed samples for some tests, Figures 5 and 6.

A standard Penetrating Test (SPT) was conducted, too. It is a common testing method used to estimate the relative density of soils and approximate shear strength parameters. The test uses a thick-walled sample tube, with an outside diameter of $50 \mathrm{~mm}$ and an inside diameter of $35 \mathrm{~mm}$, and a length of around $650 \mathrm{~mm}$ ended by a driven shoe. Tube is driven into the ground at the bottom of a borehole by blows from a slide hammer with a weight of $63.5 \mathrm{~kg}$ falling through a distance of $760 \mathrm{~mm}$.

The sample tube is driven $150 \mathrm{~mm}$ into the ground and then the number of blows needed for the tube to penetrate each $150 \mathrm{~mm}$ up to a depth of $450 \mathrm{~mm}$ is recorded. The sum of the number of blows required for the second and third 6 in. of penetration is termed the "standard penetration resistance" or the "N-value". In cases where 50 blows are insufficient to advance it through a $150 \mathrm{~mm}$ interval the penetration after 50 blows is recorded. The blow count provides an indication of the density of the ground, and it is used in many empirical geotechnical engineering formulae.

\subsection{Resistivity Imaging Works}

In order to choose the proper plans and methods for field works, study area has been surveyed by locating sites of risk phenomena using the Global Positioning System (GPS). Due to the distribution of the sink holes, survey line directions were assigned to extend from West to East, perpendicular to main lines joining these holes.

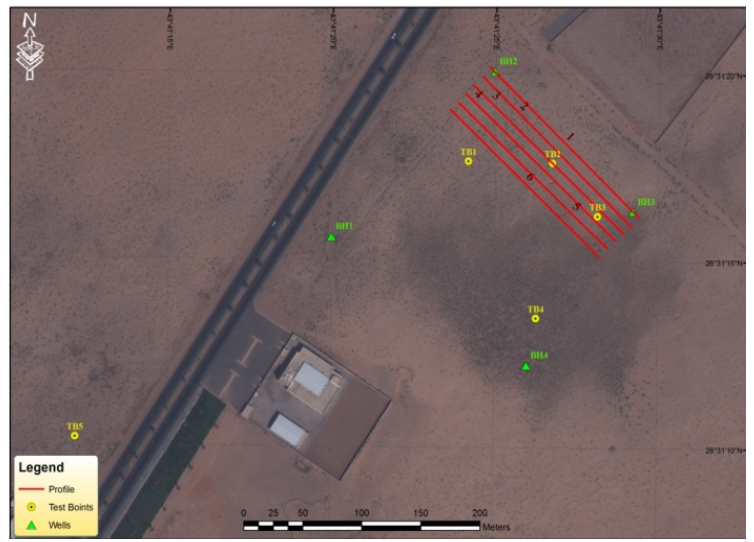

Figure 5. Satellite image showing the location of the 2D electrical resistivity profiles and borehole locations.

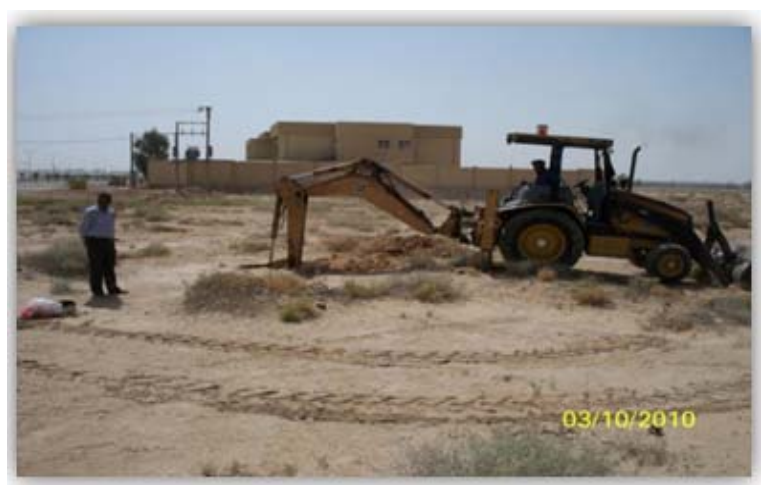

Figure 6. Digging an open hole at study area. 
The electrical resistivity survey lines were designed to be of 2 dimensions, with $177 \mathrm{~m}$ length and $3 \mathrm{~m}$ electrical node spacing. 9 parallel electrical survey lines, with 9 meters spacing distance between each other's, have been conducted, and in a way that the first survey line extends to the north of the site and the last one extends towards the south as shown in figure (5). The 2D electrical resistivity profile No. 2 shown in Figure 7 was selected to extend along a direction that crosses boreholes No. 2 and No. 3. Borehole No. 1 is situated 10 meters away from the start point of this profile, and the distance between the two wells is 157 meters.

The choice of the two borehole locations being connected with electrical section is to compare between the two methods of investigation. This will enable a double check and comparison between two different methods. The electrical resistivity lines can give information on layers to depths far greater than those obtained from the boreholes. The test locations were selected in such a way to cover the area of high risk near the school. Cavities were scattered at different places within the site. The works of [3], [4] and [5] provide a good guide for evaluating the electrical resistivity of soils.

\section{Results of Electrical Resistivity Imaging and the Geotechnical Engineering}

Results of electrical imaging tests showed that the resis- vity was low and in the order of ( $5 \Omega)$, in a vertical section ranging from earth's surface to a depth of 6 meters. This low resistivity is believed to be a result of loose sand that is almost moist and wet. Then, the resistivity increases between 7 meters depth to the bottom of profile section, indicating more cohesive sandy layers. Evaluation used the approaches and guides by [6].

These results match properly with those obtained in the geotechnical engineering work. The nature of the subsurface soil, according to what has been reported from test borings, seems to be formed of extremely dense sandy soil layers, with argillaceous, calcareous and gypsiferous cementation. The density of the sandy soil increases with depth, and gradually, soil becomes sandstone. Photos of Scanning Electron microscope (SEM) show presence of cements between the sand particles and wide interstitial spaces between quartz grains filled by the soluble gypsum (Figure 8). No groundwater has been detected in the range of tested soil layers. However, the soil layers might be water bearing ones in the pluvial intervals, long time ago, as it lies in a low depression at the foothill of nearby mountains. This study suggests that the problem is related to the nature of soil layers, near to earth's surface, that when it rains, the layer goes into loose sand liquefaction, sometimes called "running sand", causing more looseness for sand, and more widening of interstitial spaces and forming vugs that extend gradually into cracks and voids causing sudden collapses (Figure 9).

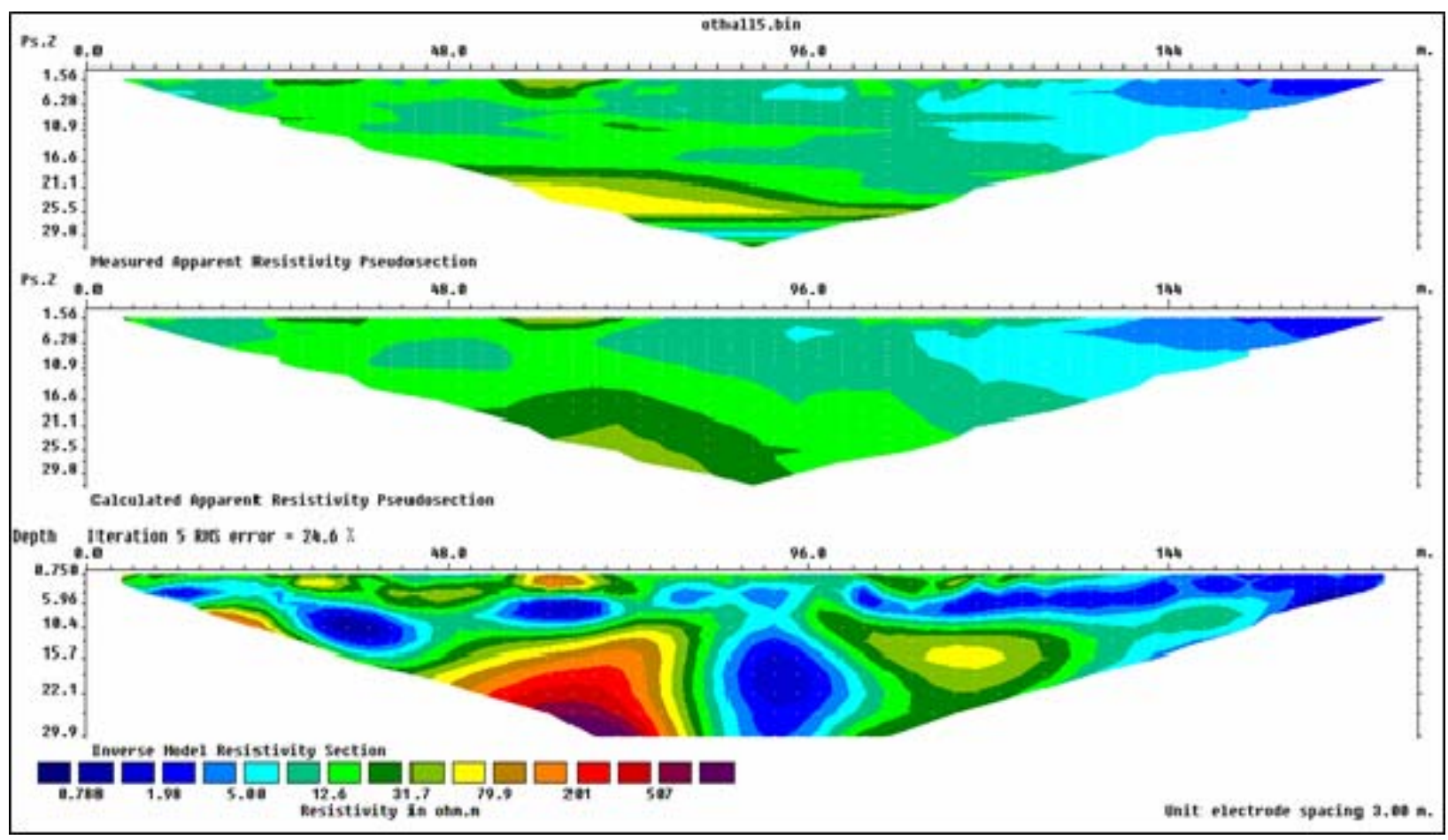

Figure 7. Typical electrical resistivity profile.

A collapse potential test was carried out for samples extracted from the test pits in accordance with ASTM D 
5333-9 [7]. The collapse Index measured at $300 \mathrm{kPa}$ stress was found $6.3 \%$ (Figure 10).

The chemical test results presented in Table 1 provide good estimates of anions and cations. Percentage of gypsum and carbonate content is significant.

ue to the chemical nature of the subsurface material and the flow of water derived by significant hydraulic gradient, it is decided to recommend some solution that will reduce the risk to the existing school.

However, one of the solutions suggested based on detailed field study, was to dig a trench with a depth ranging between 2.5 - 3 meters, with a width of $60-80$ centimeters around the local building walls, filling it with imbricated water proof insulator, then filling the empty spaces by a low permeability soil, e.g. a mixture of sand and bentonite or any appropriate clayey soil, that does not contain gravels or angular grains that could cause a damage to water proof layer. This method is known as "cut-off wall". It is effective in preventing hydraulic rush of subsurface water that would cause soil washing and pore space formation (Figure 11).

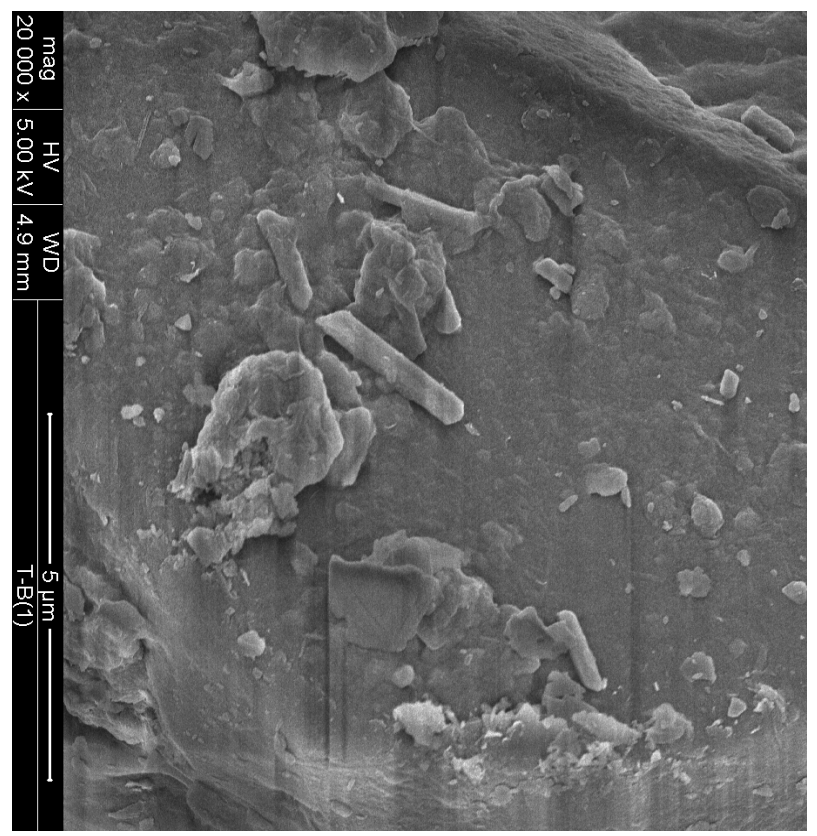

Figure 8. View of the expansive soil as seen in an SEM to 2000 magnifications.

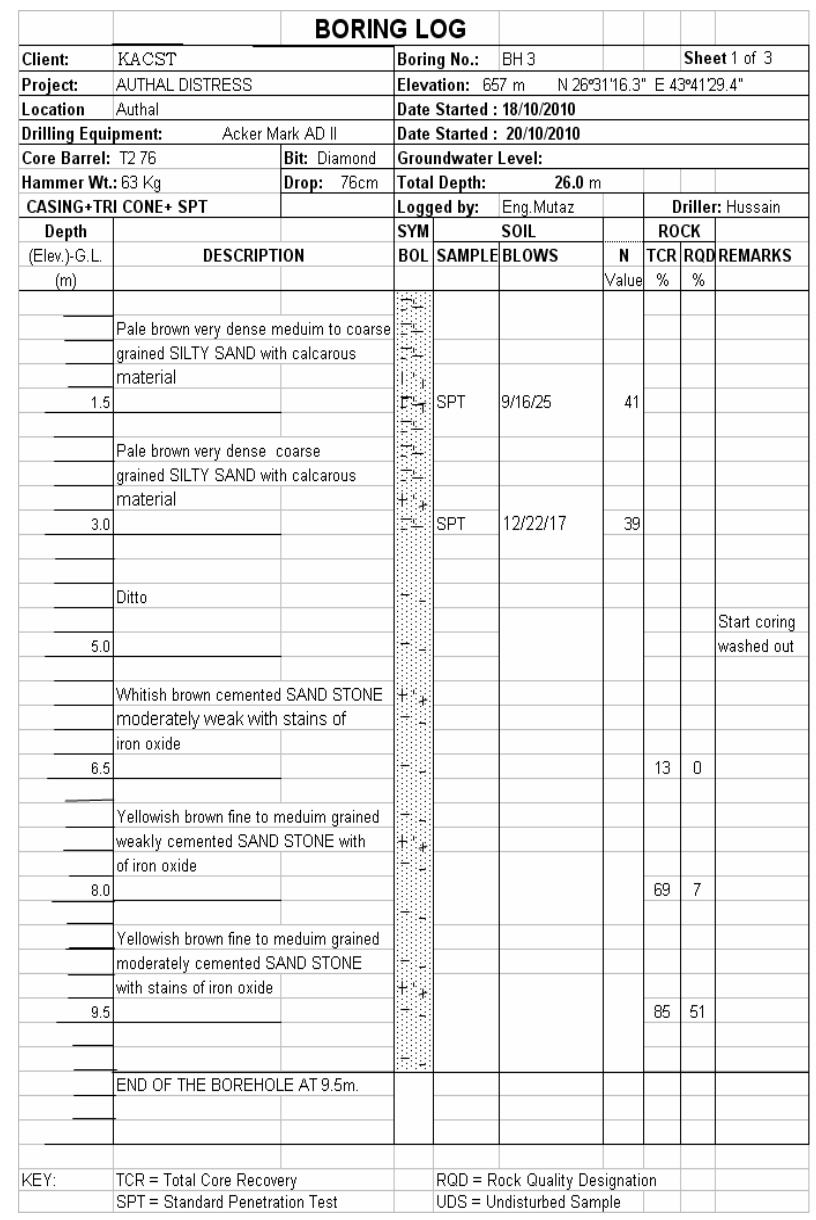

Figure 9. Typical soil profile as obtained for borehole 3.

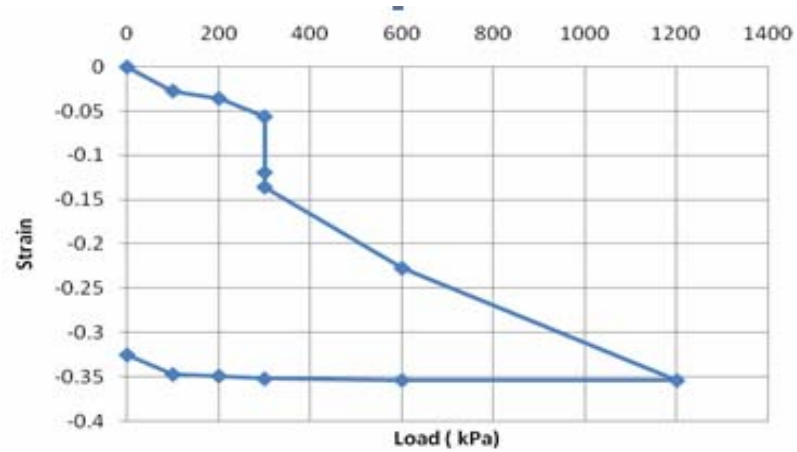

Figure 10. Collapse potential test profile.

Table 1. Chemical Tests for samples collected from TP 1, TP 2, TP 3 and TP 4.

\begin{tabular}{|c|c|c|c|c|c|c|c|c|c|c|c|c|c|c|}
\hline \multirow{2}{*}{ TP No. } & $\mathrm{Al}$ & $\mathrm{Ca}$ & $\mathrm{Fe}$ & $\mathrm{Mg}$ & $\mathrm{Si}$ & $\mathrm{Na}$ & K & $\mathrm{Cl}(*)$ & $\mathrm{Ca}-\mathrm{CO}_{3}$ & $\mathrm{CaSO}_{4} \cdot 2 \mathrm{H}_{2} \mathrm{O}$ & $\mathrm{S}$ & $\mathrm{SO}_{4}^{-2}$ & $\mathrm{NH}_{4}$ & $\mathrm{NO}_{3}$ \\
\hline & \multicolumn{14}{|c|}{$\%$} \\
\hline 1 & 1.6 & 19.6 & 0.5 & 1.1 & 34.4 & 9.6 & 1.9 & 0.20 & 13.7 & 7.8 & 1.5 & 4.5 & 5.0 & 0.6 \\
\hline 2 & 1.7 & 22.2 & 0.8 & 1.5 & 21.3 & 6.5 & 0.8 & 0.33 & 2.3 & 7.7 & 1.5 & 4.6 & 5.0 & 2.2 \\
\hline 3 & 4.4 & 13.0 & 2.3 & 1.6 & 27.6 & 3.2 & 0.6 & 0.37 & 2.1 & 8.0 & 1.6 & 4.7 & 3.9 & 1.1 \\
\hline 4 & 6.6 & 21.4 & 3.7 & 2.0 & 25.6 & 2.7 & 0.5 & 0.41 & 0.8 & 7.7 & 1.5 & 4.6 & 4.5 & 1.1 \\
\hline
\end{tabular}

* dissolved cl estimated from saturated clay paste. 


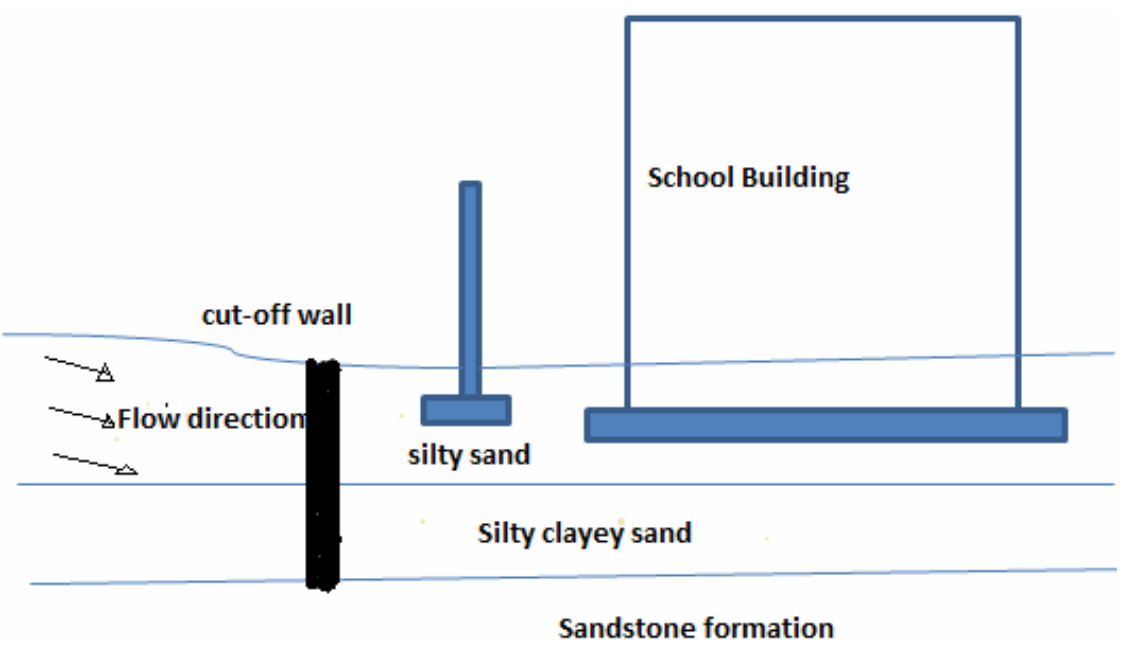

Figure 11. Schematic diagram for the proposed cut-off wall.

\section{Conclusion and Recommendation}

This study investigated the cause of cavity formation near surface and close to foundation level for a site of a school building in central parts of Saudi Arabia.

It was found that the site was rich in soluble salts which included gypsum and calcareous material. The site was also subjected to surface and subsurface water flow with a rather high hydraulic gradient. Comprehensive study using geotechnical and geophysical methods in addition to physical and chemical laboratory tests were performed.

A practical solution was suggested to solve the problem of near surface cavity formation using "cut-off wall" method. The trench with a depth of $2.5-3.0$ meters, and a width of $60-80$ centimetres, around the outside school walls filled up with a mixture of sand bentonite slurry is expected to intercept flow of water and reduce the energy of flow. The wall can be extended to a satisfactory depth where no cavities were reported. The use of water proof insulator or geotextile membrane can be used as a liner to protect fine material from being washed away. Construction of the cut-off wall all around the school will provide satisfactory protection. Rise and fall of ground water under the school will not cause any serious problems as the fines will be trapped at the bottom sandstone layer.

\section{Acknowledgements}

The authors would like to acknowledge and thank King Abdulaziz City for Science and Technology for funding this work. Thanks to extend to Eng. Mutaz Elamin and the geophysical team of KACST for conducting some activities related to this project.

\section{REFERENCES}

[1] H. Abdulrahman and Alghamdi, "An Investigation of the Structural Framework beneath Riyadh City Using Gravity and Aeromagnetic Evidence," 2007, Unpublished thesis, KSU, Riyadh.

[2] R. W. Powers, L. F. Ramirez, C. D. Redmond and E. L. Elberg, "Geology of the Arabian Penisula. Sedimentary Geology of Saudi Arabia," US Geological Survey Professional Paper, 560-D, 1966, p. 147.

[3] Z. Abu-Hassanein, C. Benson and L. Blotz, "Electrical Resisitivity of Compacted Clay," Journal of Geotechnical Engineering, Vol. 122, No. 5, 1996, pp. 397-406. doi:10.1061/(ASCE)0733-9410(1996)122:5(397)

[4] R. J. Kalinski and W. E. Kelly, "Electrical-Resistivity Measurement for Evaluation Compacted-Soil Liners.,"Journal of Geotechnical Engineering, Vol. 120, No. 2 1994, pp. 451-457. doi:10.1061/(ASCE)0733-9410(1994)120:2(451)

[5] G. L. Yoona and J. B. Parkb, "Sensitivity of Leachate and Fine Contents on Electrical Resistivity Variations of Sandy Soils," Journal of Hazardous Materials, Vol. 84, No. 2-3, 2001, pp. 147-161.

[6] W. M. Telford, L. P. Geldart and R. E. Sheriff, Applied Geophysics, second edition, Cambridge University Press, 1990. doi:10.1017/CBO9781139167932

[7] ASTM, American Standard Testing Methods, 2002, ASTM D 2487and ASTM D 5333. Annual Book of ASTM Standards, Vol. 04.08. 